\title{
Desenvolvimento e produção de melão Cantaloupe em função do espaçamento e ambientes de cultivo no Cerrado brasileiro
}

\section{Development and production of Cantaloupe melon as a function of plant spacing and growing environments in the Brazilian Cerrado}
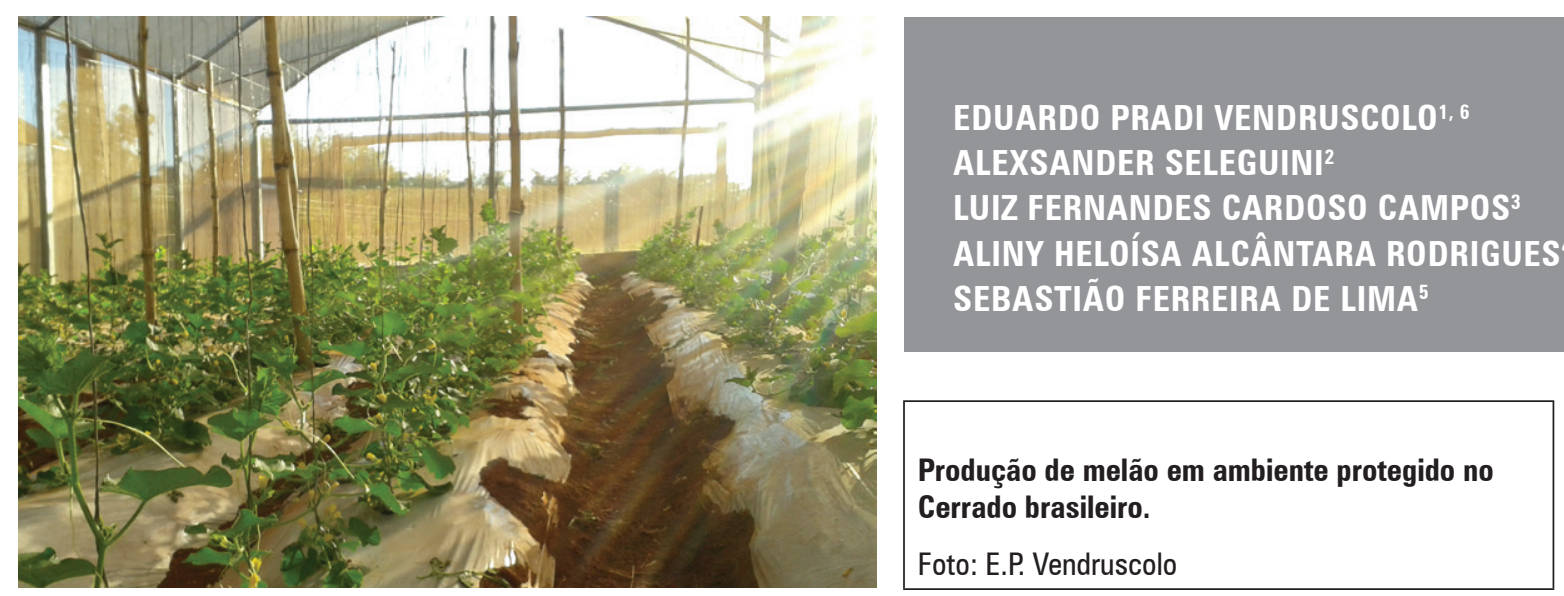

\section{RESUMO}

A cultura do melão é responsiva ao ambiente de cultivo e às técnicas de produção utilizadas, sendo estes fatores cruciais para a obtenção de frutos de maior qualidade. Desta forma, objetivou-se estudar, o crescimento vegetativo, o potencial produtivo e a qualidade de frutos de meloeiro Cantaloupe em função da redução do espaçamento em dois ambientes de cultivo. Em delineamento experimental de blocos ao acaso, plantas de meloeiro, cultivar Trinity, foram cultivadas em campo aberto e ambiente protegido, sob cinco espaçamentos entre plantas $(15,25,35$, 45 e $55 \mathrm{~cm})$. Observou-se que a taxa de crescimento de plantas, a taxa de emissão foliar, bem como a espessura de casca e polpa, o teor de sólidos solúveis, e o ratio foram superiores sob cultivo protegido. Em relação aos espaçamentos, verificou-se que seu aumento influenciou, de forma linear e positiva, as características de massa seca de plantas, massa fresca de frutos e espessura da polpa. No entanto, o aumento da densidade de plantas aumentou a produtividade. Para velocidade de crescimento, velocidade de

1 Unidade Universitária de Cassilândia, Universidade Estadual de Mato Grosso do Sul (UCC/UEMS), Cassilândia-MS (Brasil). ORCID Vendruscolo, E.P.: 0000-0002-3404-8534

2 Campus Universitário de Iturama, Universidade Federal do Triângulo Mineiro (UFTM), Iturama-MG (Brasil). ORCID Seleguini, A.: 0000-0002-5762-9278

3 Campus São Luís de Montes Belos, Universidade Estadual de Goiás (UEG), São Luís de Montes Belos-GO (Brasil). ORCID Campos, L.F.C.: 0000-0001-5171-5194

4 Escola de Agronomia, Universidade Federal de Goiás (EA/UFG), Goiânia-GO (Brasil). ORCID Rodrigues, A.H.A.: 0000-0002-3061-5730

5 Campus de Chapadão do Sul, Universidade Federal de Mato Grosso do Sul (CPCS/UFMS), Chapadão do Sul-MS (Brasil). ORCID Lima, S.F.d.: 0000-0001-5693-912X

6 Autor para correspondência. agrovendruscolo@gmail.com 
emissão foliar e comprimento e circunferência de fruto constataram-se pontos de máximos de 47,50; 53,75; 49,95 e $47,51 \mathrm{~cm}$, respectivamente. Em vista dos resultados, para regiões com condições semelhantes à do presente estudo, o cultivo do meloeiro Cantaloupe é favorecido em condições de cultivo protegido e espaçamentos entre 45 e $55 \mathrm{~cm}$ na linha de plantio.

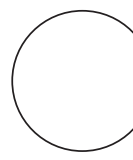
Palavras-chave adicionais: Cucumis melo var. reticulatus Naud, melão rendilhado,
bioma Cerrado, fator ambiental, densidade de plantio.

\section{ABSTRACT}

Melon is responsive to the cultivation environment and the production techniques that are used, factors crucial for obtaining high quality fruits. The objective of this research was to study the vegetative growth, productive potential and quality of Cantaloupe melon fruits as a function of a reduction of spacing in two growing environments. Using a randomized block design, melon plants (cv. Trinity) were cultivated in an open field and a protected environment, with five different spacing between plants $(15,25,35,45$ and $55 \mathrm{~cm})$. It was observed that the plant growth rates, leaf emission rate, thickness of bark and pulp, total soluble solids content, and ratio were higher with the protected cultivation. For spacing, the increase influenced, in a linear and positive manner, the characteristics of dry mass of plants, fresh mass of fruits and thickness of the pulp. However, increasing the plant density increased productivity. For growth velocity, foliar emission velocity and fruit length and circumference, maximum points were observed when the plants were spaced at 47.50, 53.75, 49.95 and $47.51 \mathrm{~cm}$ from each other, respectively. Considering these results, for regions with similar conditions to the present study, the cultivation of the Cantaloupe melon is favored when conducted under protected cultivation conditions, with a plant spacing between 45 and $55 \mathrm{~cm}$.

Additional key words: Cucumis melo var. reticulatus Naud, muskmelon, Cerrado biome, environmental factor, planting density.

Data de recepção: 24-10-2017 Aprovado para publicação: 30-05-2018

INTRODUÇÃO

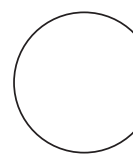

Nos últimos anos o Brasil apresentou crescimento expressivo na produção de melões, passando de 350.000 t em 2003 para cerca de 521.000 t anuais em 2015, produzidos em uma área equivalente a 21.000 ha, resultando em uma produtividade média anual de $24,8 \mathrm{t} \mathrm{ha}^{-1}$. Apesar do cultivo de melão ser possível em praticamente todo o território brasileiro, a região Nordeste destaca-se como principal polo produtivo, detendo mais de $94,7 \%$ da produção nacional (IBGE, 2015; Vendruscolo et al., 2017a).

No estado de Goiás a produção de melão é inexpressiva (IBGE, 2015), porém, apresenta excelentes condições ambientais para a exploração comercial da cultura, notadamente no outono inverno, dada a combinação de altas temperaturas com ausência de chuvas. Esta característica climática lhe confere aptidão para o cultivo do meloeiro, pois a qualidade dos frutos é favorecida por condições de altas temperaturas e baixa umidade relativa do ar (Monteiro, 1995; Bardiviesso et al., 2015).

Dentre os meloeiros cultivados, há um crescente interesse pela produção de frutos tidos como "nobres", conhecidos popularmente como melão japonês ou Cantaloupe, os quais são pertencentes aos melões rendilhados (Cucumis melo var. reticulatus Naud.) do grupo Cantalupensis. Estes melões possuem qualidades superiores quanto ao aroma, polpa com coloração diferenciada, maior teor de sólidos solúveis em 
comparação aos melões tradicionais (Medeiros et al., 2007).

A busca por produtos advindos de cultivos menos impactantes ao meio-ambiente também vem aumentando à medida que há possibilidade de disponibilizar informações de procedência aos consumidores. Estes optam por frutos produzidos com menor necessidade do uso de agrotóxicos e em sistema com maior eficiência na utilização da água e nutrientes. $\bigcirc$ ambiente protegido apresenta estas características em vantagem ao cultivo realizado diretamente em campo aberto, como a proteção contra fatores bióticos e abióticos (Chang et al., 2013). No entanto, outras técnicas podem ser implantadas visando o melhor aproveitamento do espaço e dos recursos envolvidos.

Dentre as técnicas de cultivo, o adensamento no plantio pode ser utilizado como estratégia para otimizar o uso da terra e obter frutos com características apreciadas em diferentes mercados consumidores. Para minimelancias, foi observado menor desenvolvimento de plantas e frutos em sistemas de plantio adensado, o qual, no entanto, resultou em maiores produtividades por área cultivada (Campagnol et al., 2016). Resultado similar foi obtido para três cultivares de melão, em sistema de cultivo protegido, em que a produção foi incrementada em $34,6 \%$ e a massa de frutos decresceu $11,4 \%$ pelo cultivo em $0,3 \mathrm{~m}$ entre plantas, em relação ao cultivo com espaçamento de $0,5 \mathrm{~m}$ (Bezerra et al., 2009). Soma-se ao adensamento o cultivo de plantas verticalizadas, o qual traz uma série de benefícios como a facilitação do manejo de pragas e doenças (Martins et al., 1999; Chang et al., 2013), além de melhorar as qualidades físico-químicas dos frutos (Martins et al., 1998) e a ergometria da atividade para o trabalhador rural.

Para melões rendilhados, deve-se levar em conta a preferência do consumidor em relação, principalmente, ao tamanho de frutos. Uma vez que, segundo Santos et al. (2015), são considerados comercializáveis frutos firmes, uniformes quanto à cor, com bom rendilhamento de casca, sem deformações, murchamento, rachaduras, sinais de podridão, ataques de insetos ou pragas e danos mecânicos.

O cultivo de novas áreas produtivas demanda informações quanto ao desenvolvimento da cultura e aos tratos que venham a aperfeiçoar o sistema de produção. Para tanto, neste trabalho objetivou-se estudar, o crescimento vegetativo, o potencial produtivo e a qualidade de frutos de meloeiro Cantaloupe em função da redução do espaçamento em dois ambientes de cultivo.

\section{MATERIAL E MÉTODOS}

O estudo foi conduzido de setembro a novembro do ano de 2015, em Goiânia, Goiás, situado na região central do Brasil, 16 $40^{\prime} \mathrm{S}$ and $49^{\circ} 15^{\prime} \mathrm{W}$ e altitude de $750 \mathrm{~m}$. O local apresenta clima Aw, segundo classificação de Köppen-Geiger (Cardoso et al., 2014), caracterizado por clima tropical com estação chuvosa de outubro a abril e um período com precipitações inferiores a $100 \mathrm{~mm}$ mensais entre maio a setembro. As temperaturas médias mensais variam de $20,8^{\circ} \mathrm{C}$, nos meses de junho e julho, a $25,3^{\circ} \mathrm{C}$ no mês de outubro (Cardoso et al., 2014). Os registros climáticos da temperatura e umidade do ar durante a condução do experimento foram obtidos a partir de estação climática localizada a $200 \mathrm{~m}$ do local dos ensaios (Fig. 1).

O solo da área experimental, nos dois ambientes de cultivo, foi classificado como Latossolo Vermelho (Santos et al., 2013) e apresentou as seguintes características químicas, determinadas a partir da recomendação encontradas no manual de análises de solo (Donagemma et al., 2011): M.O. = 0,7\%; pH $\left(\mathrm{CaCl}_{2}\right)$ $=4,6 ; \mathrm{P}$ (Mehlich) = 3,5 $\mathrm{mg} \mathrm{dm}^{-3} ; \mathrm{K}=131,0 \mathrm{mg} \mathrm{dm}^{-3}$; $\mathrm{Ga}=2,0 \mathrm{cmolc} \mathrm{dm}^{-3} ; \mathrm{Mg}=0,81 \mathrm{cmolc} \mathrm{dm}^{-3} ; \mathrm{H}+\mathrm{Al}$ $=2,5 \mathrm{cmolc} \mathrm{dm}^{-3} ; \mathrm{Al}=0,0$ cmolc $\mathrm{dm}^{-3} ; \mathrm{CTC}=5,6$ cmolc dm ${ }^{-3} ; \mathrm{m} \%=0,0 ; \mathrm{V} \%=55,7$.

O experimento foi delineado em blocos ao acaso em esquema fatorial $5 \times 2$, em que o primeiro fator corresponde aos cinco espaçamentos entre plantas (15, $25,35,45,55 \mathrm{~cm})$ e segundo fator aos dois ambientes de produção (protegido e campo aberto), com quatro repetições. Cada parcela foi constituída por uma linha de $3,5 \mathrm{~m}$ de comprimento. $\mathrm{O}$ ambiente protegido apresentava comprimento de $21 \mathrm{~m}$, largura de $7 \mathrm{~m}$, totalizando $147 \mathrm{~m}^{2}$, e altura de $4 \mathrm{~m}$, coberto com filme plástico transparente e tela antiofídica branca nas laterais. $O$ ambiente continha ainda duas aberturas nas extremidades, equivalentes ao arco superior. As mudas foram obtidas em bandejas de poliestireno expandido, a partir da semeadura em substrato turfoso comercial e húmus de minhoca (3:1) de sementes da cultivar Trinity (Takii Seed, Kyoto, Japão), no dia 21 de julho de 2015. Aos 35 d após a semeadura as mudas foram transplantadas para canteiros previamente preparados, com $20 \mathrm{~cm}$ de altura e $55 \mathrm{~cm}$ de largura, recobertos com mulching plástico de cor branca e distantes $80 \mathrm{~cm}$ entre si. $O$ transplantio tardio $(35 \mathrm{~d}$ ) 


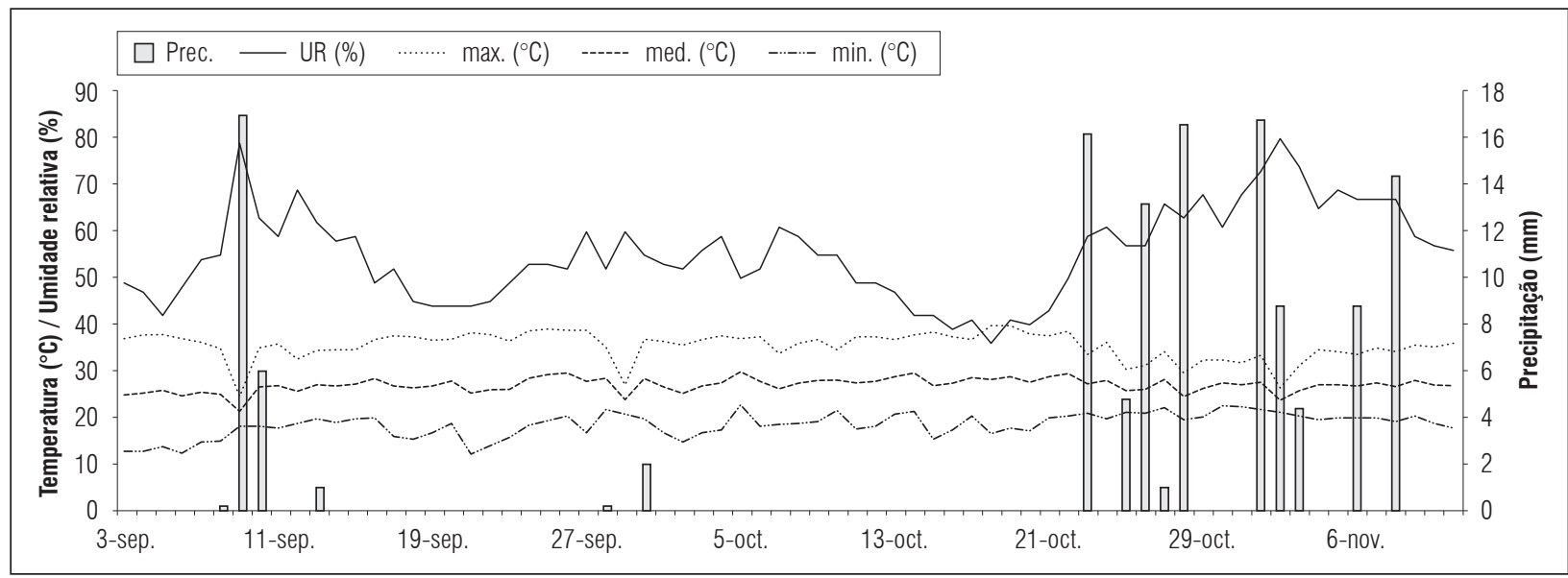

Figura 1. Condições climáticas de umidade relativa do ar, precipitação e temperatura máxima, média e mínima durante o período de condução do estudo.

se deu por ocasião das baixas temperaturas na época em que as mudas foram produzidas, atrasando seu desenvolvimento.

A condução foi montada em sistema de espaldeira utilizando-se mourões de eucalipto que serviram como ponto de fixação dos arames tensionados sobre as linhas de plantio. O tutoramento das plantas de meloeiro e dos frutos foi feito por meio de fitilho amarrado ao arame tensionado a 2,5 $\mathrm{m}$ de altura. A irrigação foi realizada por meio de sistema de gotejamento. Para tanto foi utilizada uma mangueira por canteiro, está contendo gotejadores espaçados $20 \mathrm{~cm}$ entre si. Por meio deste sistema também foram realizadas as adubações de cobertura, via fertirrigação, aplicando-se $80 \mathrm{~kg} \mathrm{ha}^{-1} \mathrm{de} \mathrm{N}$, na forma de ureia dissolvida, e $80 \mathrm{~kg} \mathrm{ha}^{-1} \mathrm{de}_{2} \mathrm{O}_{5}$, parcelados em duas épocas, aos 33 e aos $54 \mathrm{~d}$ após o plantio.

Trinta dias após o transplantio, foi avaliado o índice relativo de clorofila (SPAD), com clorofilômetro portátil (CFL1030; Falker, Porto Alegre-RS, Brasil), utilizando a terceira folha totalmente expandida, enquanto que a avaliação das demais características biométricas das plantas foi realizada aos $45 \mathrm{~d}$ após o transplantio, quando foram obtidos os valores de altura e número de entrenós das plantas. A partir desses valores foram obtidos os valores de velocidade de crescimento $(\mathrm{cm}$ $\mathrm{d}^{-1}$ ) e velocidade de emissão foliar (folhas/dia), pela razão entre a altura máxima e do número máximo de nós, respectivamente, pelo número de dias ( $45 \mathrm{~d})$, de três plantas por parcela.

Ao final do ciclo, $63 \mathrm{~d}$ após o transplantio das mudas, foram avaliadas as características de produtividade e qualidades físico-químicas de três frutos por parcela. Para tanto, foi observada a produtividade por metro quadrado, mensurados a massa fresca por pesagem em balança (W15, Welmy, Sta. Bárbara d'Oeste-SP, Brasil), a circunferência e o comprimento do fruto com fita métrica, espessura da casca e da polpa com paquímetro digital (Metrotools, São Paulo-SP, Brasil) e avaliadas as características químicas de sólidos solúveis por meio da leitura em refratômetro manual RTA-50 (Instrutherm, São Paulo-SP, Brasil), acidez titulável obtida pela titulação com solução de $\mathrm{NaOH}$ (1 M) e pela relação entre essas últimas duas variáveis foi obtida a relação entre sólidos solúveis e a acidez titulável (ratio). Também nesse momento obteve-se massa de matéria seca das mesmas três plantas por parcela. As plantas foram cortadas à altura do colo, colocadas em sacos de papel pardo e acondicionadas em estufa de ventilação forçada à temperatura de $70^{\circ} \mathrm{C}$ até a observação de massa constante e, posteriormente, pesada em balança digital (ML 600, Marte, São Paulo-SP, Brasil).

Os resultados foram submetidos à análise de variância e as médias de ambientes pelo teste de Tukey $(P \leq 0,05)$, e realizando-se as análises de regressão para descrição dos efeitos dos espaçamentos. Para tanto utilizou-se o programa estatístico Sisvar (Ferreira, 2014).

\section{RESULTADOS E DISCUSSÃO}

Para as características biométricas e produtivas foram observadas diferenças significativas $(P \leq 0,05)$ para os ambientes de cultivo e espaçamentos entre plantas 
para todas as variáveis, excetuando-se o índice relativo de clorofila, para a qual não foram constatadas diferenças para espaçamento entre plantas (Tab. 1).

Foi observado que a velocidade de crescimento e a velocidade de emissão foliar foram maiores em plantas cultivadas ambiente protegido, quando comparadas às plantas cultivadas em campo aberto (Tab. 1). 0 ambiente protegido representa uma série de vantagens que favorece o desenvolvimento dos vegetais. Dentre as quais, a formação de um microclima com maior umidade, que diminui a evapotranspiração dos vegetais, a barreira física criada pelas telas laterais, que dificultam a entrada de insetos e a proteção contra o excesso de radiação solar (Chang et al., 2013; Purquerio e Tivelli, 2006).

$O$ aumento do espaçamento de plantio proporcionou maior velocidade de crescimento, até o ponto máximo estimado em $47,5 \mathrm{~cm}$, no qual se obteve um crescimento diário de $3,87 \mathrm{~cm}$. A variável velocidade de emissão foliar seguiu a mesma tendência, na qual foi constatado um ponto máximo de $53,75 \mathrm{~cm}$ entre plantas, com emissão de 0,61 folhas/dia (Tab. 1).

Para a massa de matéria seca de plantas, foi verificada resposta crescente ao aumento do espaçamento entre plantas, em que o maior acúmulo de matéria seca coincidiu com o maior espaçamento. $O$ mesmo comportamento foi observado para a variável massa fresca de frutos, verificando-se aumento em razão do aumento de espaçamento entre plantas (Tab. 1).

Esses resultados corroboram com as observações realizadas por Silva et al. (2010) ao estudar o efeito da densidade de plantio sobre o desenvolvimento de plantas de pimentão. Os autores verificaram que a diminuição da densidade de plantio resultou em maior desenvolvimento de plantas e frutos, atribuídos à menor competitividade entre os vegetais. Segundo Sangoi et al. (2002), a diminuição da competição entre plantas no ambiente, por nutrientes, água e radiação solar pode resultar em maior aporte de carbono e nitrogênio, favorecendo o desenvolvimento vegetativo.

Os valores do índice relativo de clorofila foram maiores em folhas de plantas cultivadas em ambiente protegido (Tab. 1). A elevação no índice relativo de clorofila pode ser explicada pela compensação realizada pelas plantas quanto ao sombreamento proveniente da cobertura plástica. Pois o maior teor de clorofila, principalmente da clorofila $b$, permite o aproveitamento de luz menos intensa, incrementando o desenvolvimento dos vegetais em ambientes sombreados (Whatley e Whatley, 1982).

Tabela 1. Médias de velocidade de crescimento (VC), velocidade de emissão foliar (VEF), matéria seca de plantas (MS), índice relativo de clorofila (IRC), massa fresca de frutos (MFF) e produtividade (PROD) para plantas de meloeiro cultivadas em diferentes ambientes e espaçamentos entre plantas. Goiânia- G0, 2015.

\begin{tabular}{|c|c|c|c|c|c|c|}
\hline \multirow{2}{*}{ Fatores de variação } & VC & VEF & MS & IRC & MFF & PROD \\
\hline & $\left(\mathrm{cm} \mathrm{d}^{-1}\right)$ & (Folhas/dia) & (g) & (SPAD) & $(\mathrm{kg})$ & $\left(\mathrm{kg} \mathrm{m}^{-2}\right)$ \\
\hline \multicolumn{7}{|c|}{ Ambientes de cultivo } \\
\hline Protegido & $4,38 \mathrm{a}$ & 0,67 a & 44,66 a & 64,85 a & $1,33 \mathrm{a}$ & $4,77 \mathrm{a}$ \\
\hline Campo & $3,10 \mathrm{~b}$ & $0,51 \mathrm{~b}$ & $42,04 \mathrm{a}$ & $56,27 b$ & $1,23 \mathrm{a}$ & $4,58 \mathrm{a}$ \\
\hline \multicolumn{7}{|c|}{ Espaçamento entre plantas } \\
\hline 15 & 3,48 & 0,55 & 26,21 & 59,55 & 0,89 & 6,87 \\
\hline 25 & 3,72 & 0,58 & 44,43 & 61,27 & 1,22 & 5,70 \\
\hline 35 & 3,72 & 0,59 & 40,76 & 59,26 & 1,33 & 4,44 \\
\hline 45 & 3,95 & 0,62 & 51,82 & 60,87 & 1,43 & 3,34 \\
\hline 55 & 3,82 & 0,61 & 53,55 & 61,84 & 1,51 & 3,04 \\
\hline Regressão linear & NS & NS & $* 3$ & NS & $* 4$ & $* 5$ \\
\hline Regressão quadrática & $* 1$ & $* 2$ & NS & NS & NS & NS \\
\hline CV\% & 13,1 & 11,54 & 22,99 & 11,26 & 17,85 & 17,33 \\
\hline
\end{tabular}

Médias seguidas pela mesma letra nas colunas não diferem entre si a $5 \%$ de probabilidade pelo teste de Tukey. ${ }^{*}$, NS: significativo a $P \leq 0,05$ e não significativo, respectivamente.

${ }^{1} \mathrm{Y}=-0,0004 \mathrm{x}^{2}+0,0344 \mathrm{x}+3,0521 R^{2}=0,8521 ;{ }^{2} \mathrm{Y}=-4 \mathrm{E}-05 \mathrm{x}^{2}+0,0043 \mathrm{x}+0,4963 R^{2}=0,954 ;{ }^{3} \mathrm{Y}=0,6206 \mathrm{x}+21,633 R^{2}=0,8068 ;{ }^{4} \mathrm{Y}=0,0145 \mathrm{x}+$ $0,7684 R^{2}=0,9078 ;{ }^{5}-1002,2 \mathrm{x}+81835 R^{2}=0,9672$ 
A produtividade foi afetada negativamente com o aumento do espaçamento entre plantas, observando-se efeito decrescente (Fig. 2). Isso é devido ao menor número de plantas por área e, consequentemente, menor quantidade de frutos. Resultado semelhante foi observado para diferentes cultivares de melancia, em que maiores densidades de plantio favoreceram

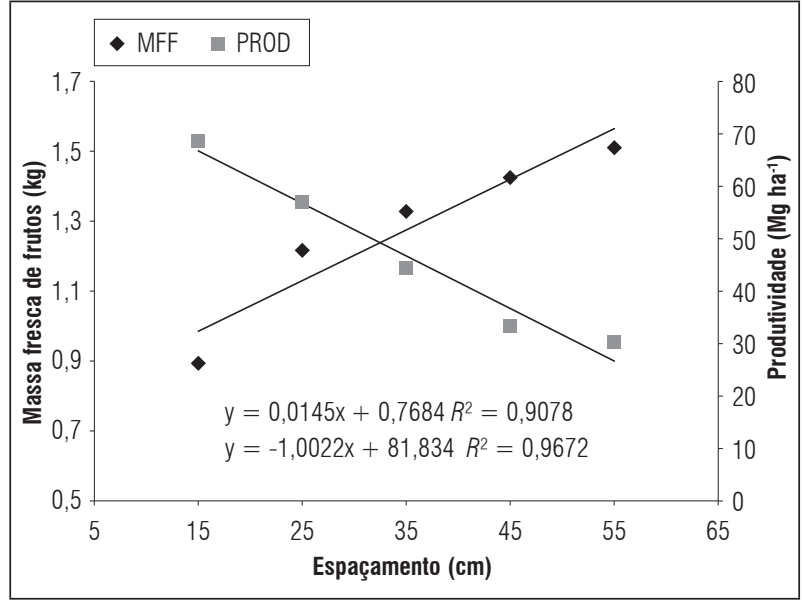

Figura 2. Massa fresca de frutos e produtividade para plantas de meloeiro cultivadas em diferentes ambientes e espaçamentos entre plantas. Goiânia-G0, 2015. o aumento da produtividade por área (Ramos et al., 2009). Ao serem relacionadas, a produtividade e a massa fresca de frutos, obtém-se que o aumento da densidade de plantio resulta em maior quantidade de frutos de menor tamanho (Fig. 2). Resultados semelhantes foram obtidos para a cultura do meloeiro, em que plantas de três cultivares foram conduzidas em espaçamentos de 0,3 e 0,5 cm entre plantas, para o qual foi observado o efeito de elevação da massa dos frutos em maior espaçamento de plantio, enquanto que nessa mesma condição houve uma redução da produtividade (Bezerra et al., 2009).

Assim como observado para as características biométricas vegetativas, houve diferenças para todas as variáveis físico-químicas, com exceção da circunferência e da acidez titulável, para os ambientes de cultivo. E para os espaçamentos entre plantas não foram observadas respostas para as características de espessura da casca, sólidos solúveis, acidez titulável e ratio (Tab. 2).

Para o comprimento e a circunferência dos frutos obteve-se resposta aos espaçamentos entre plantas. Os pontos de máximo foram obtidos nos espaçamentos de 49,95 e 47,51 cm, quando se observou valores de 15,10 e $44,00 \mathrm{~cm}$ de comprimento e circunferência, respectivamente. Resultados semelhantes foram

Tabela 2. Médias de espessura da casca (CASCA), espessura de polpa (POLPA), comprimento dos frutos (COMP), circunferência dos frutos (CIRC), sólidos solúveis (SS) e razão SS/acidez titulável (ratio) para frutos provenientes de plantas de meloeiro cultivadas em diferentes ambientes e espaçamentos entre plantas. Goiânia-G0, 2015.

\begin{tabular}{|c|c|c|c|c|c|c|}
\hline Fatores de variação & Casca & Polpa & Comp & Circ & SS & Ratio \\
\hline & $(\mathrm{mm})$ & $(\mathrm{mm})$ & (cm) & (cm) & ('Brix) & - \\
\hline \multicolumn{7}{|c|}{ Ambientes de cultivo } \\
\hline Protegido & $1,44 \mathrm{a}$ & 39,61 a & $13,80 \mathrm{~b}$ & $41,37 a$ & $7,84 \mathrm{a}$ & $17,33 \mathrm{a}$ \\
\hline Campo & $1,12 b$ & $36,80 \mathrm{~b}$ & $14,63 \mathrm{a}$ & 42,66 a & $6,49 b$ & $14,90 \mathrm{~b}$ \\
\hline \multicolumn{7}{|c|}{ Espaçamento entre plantas } \\
\hline 15 & 1,23 & 34,35 & 12,49 & 37,47 & 7,03 & 16,89 \\
\hline 25 & 1,33 & 37,22 & 14,11 & 42,11 & 7,10 & 16,23 \\
\hline 35 & 1,19 & 38,96 & 14,78 & 43,34 & 7,17 & 16,12 \\
\hline 45 & 1,28 & 39,32 & 14,51 & 42,80 & 7,23 & 16,00 \\
\hline 55 & 1,37 & 41,16 & 15,18 & 44,35 & 7,30 & 15,89 \\
\hline Regressão linear & NS & $* 1$ & NS & NS & NS & NS \\
\hline Regressão quadrática & NS & NS & $* 3$ & $*_{4}$ & NS & NS \\
\hline CV\% & 20,34 & 10,59 & 10,62 & 8,14 & 15,36 & 20,75 \\
\hline
\end{tabular}

Médias seguidas pela mesma letra nas colunas não diferem entre si a $5 \%$ de probabilidade pelo teste de Tukey. ${ }^{*}$, NS: significativo a $P \leq 0,05$ e não significativo, respectivamente.

${ }^{1} Y=0,1573 x+32,697 R^{2}=0,9367 ;{ }^{2} Y=0,1886 x+33,142 R^{2}=0,9488 ;{ }^{3} Y=-0,002 x^{2}+0,1998 x+10,11 R^{2}=0,9057$

${ }^{4} Y=-0,0057 x^{2}+0,5416 \mathrm{x}+31,139 R^{2}=0,8917$. 
obtidos para os cultivares Tânia (grupo amarelo), Gilat e Rita (grupo Cantaloupe), para os quais foi observado comprimento de frutos cultivados em espaçamento de 0,50 m entre plantas, em comparação a frutos cultivados em espaçamento de $0,30 \mathrm{~m}$ (Bezerra et al., 2009) e para o cultivar Gold Pride (grupo Valenciano), verificando-se a queda linear do comprimento e da largura dos frutos a medida em que aumentou-se a densidade de plantas de 7.000 para 25.000 plantas/ ha (Silva et al., 2003). Os autores relacionam o efeito à competição entre plantas por nutrientes, água e luz.

Observou-se que os frutos produzidos em ambiente protegido apresentaram maiores espessuras de casca e polpa e menor comprimento de frutos. Este resultado indica que nestas condições há um melhor desenvolvimento da parte comestível dos frutos, melhorando seu aproveitamento. Também, o espessamento da casca é em fator determinante à manutenção da qualidade e prevenção contra danos mecânicos durante a fase de trânsito da fruta, englobando manuseio na colheita, embalagem e transporte (Queiroga et al., 2013). Portanto, pode-se inferir que o ambiente protegido favorece a manutenção da qualidade do fruto durante as etapas pós-colheita.

Para as variáveis de sólidos solúveis e ratio, foi observada a melhora da qualidade dos frutos quando estes são provenientes de cultivo protegido. Uma das possíveis causas da menor qualidade físico-química dos frutos produzidos a campo seria a ocorrência de chuvas durante o período de enchimento e maturação. Mesmo com a utilização de mulching, o deslocamento lateral da água no solo pode ter reduzido o aproveitamento dos nutrientes advindos da fertirrigação, uma vez que nitrogênio e potássio são altamente móveis na solução do solo (Prado, 2008). Observa-se que esses nutrientes possuem alta influência sobre características como produção, espessura de polpa, sólidos solúveis e acidez titulável total (Silva et al., 2014).

A região centro-oeste do Brasil apresenta características edafoclimáticas que possibilitam a produção de melões Cantaloupe. Observa-se que há necessidade de novos estudos quanto aos tratos culturais que possibilitem melhorias na qualidade dos frutos, tais como adubação e manejo da irrigação. A exploração de cultivos diferenciados é uma oportunidade para geração de diversificação da produção nas propriedades rurais, incremento da renda e geração de empregos no meio rural pela necessidade de mão-de-obra.
Desta maneira, o melão Cantaloupe pode ser uma opção rentável ao produtor rural (Vendruscolo et al., 2017b). Também os resultados obtidos no presente estudo podem ser utilizados para a melhoria da qualidade dos frutos, levando-se em consideração o cultivo em ambiente protegido e utilizando-se do espaçamento para a exploração de diferentes mercados, com diferentes demandas quanto ao tamanho dos frutos.

\section{CONCLUSÕES}

O cultivo em ambiente protegido melhora as características biométricas e produtivas das plantas de meloeiro Cantaloupe.

Maiores espaçamentos entre plantas propiciam o aumento do tamanho dos frutos, sem afetar a qualidade dos mesmos.

O espaçamento entre plantas de 45 a $55 \mathrm{~cm}$ em condições de cultivo semelhantes às observadas no estudo é o mais indicado para a cultura do meloeiro Cantaloupe.

\section{AGRADECIMENTOS}

À Coordenação de Aperfeiçoamento de Pessoal de Nível Superior (CAPES) pela concessão da bolsa de Doutorado ao primeiro autor.

Conflito de interesses: o manuscrito foi preparado e revisado com a participação de todos os autores, que declaram não ter qualquer conflito de interesses que possa afetar a validade dos resultados do trabalho apresentado.

\section{REFERÊNCIAS BIBLIOGRÁFICAS}

Bardiviesso, D.M., W.I. Maruyama, L.E. Pessato, A.C.B. Pereira e J.H. Modesto. 2015. Adubação potássica na produção de duas cultivares de meloeiro. Rev. Agric. Neotrop. 2(1), 32-40.

Bezerra, F.M.L., M.D.C.H. Nunes, C.A.S. Freitas e F.L. Silva. 2009. Desempenho de três híbridos de meloeiro sob dois espaçamentos em ambiente protegido na Chapada do Apodi. Rev. Ciênc. Agron. 40(3), 412-416.

Campagnol, R., R.T. Matsuzaki e S.C. Mello. 2016. Condução vertical e densidade de plantas de minimelancia em ambiente protegido. Hortic. Bras. 34(1), 137-143. Doi: 10.1590/S0102-053620160000100021 
Cardoso, M.R.D., F.F.N. Marcuzzo e J.R. Barros. 2014. Classificação climática de Köppen-Geiger para o estado de Goiás e o Distrito Federal. Acta Geog. 8(16), 40-55.

Chang, J., X. Wu, Y. Wang, L.A. Meyerson, B. Gu, Y. Min, H. Xue, C. Peng e Y. Ge. 2013. Does growing vegetables in plastic greenhouses enhance regional ecosystem services beyond the food supply? Front. Ecol. Environ. 11(1), 43-49. Doi: 10.1890/100223

Donagemma G.K., V.D.B. Campos, S.B. Calderano, W.G. Teixeira e J.H.M. Viana. 2011. Manual de métodos de análise de solo. $2^{\mathrm{a}}$ ed. Brasileira de Pesquisa Agropecuária, Rio de Janeiro, Brasil.

Ferreira, D.F. 2014. Sisvar: a guide for its bootstrap procedures in multiple comparisons. Ciênc. Agrotecnol. 38(2), 109-112. Doi: 10.1590/S1413-70542014000200001

IBGE (Instituto Brasileiro de Geografia e Estatística). 2015. Sistema IBGE de Recuperação Automática - SIDRA. Em: www.sidra.ibge.gov.br; accesado: Fevereiro de 2016.

Martins, S.R., H.S. Fernandes, F.N. Assis e M.E.G. Mendez. 1999. Caracterização climática e manejo de ambientes protegidos: a experiência brasileira. Inf. Agrop. 20(1), 15-23.

Martins, S.R., R.M. Peil, J.E. Schwengber, F.N. Assis e M.E.G. Mendez. 1998. Produção de melão em função de diferentes sistemas de condução de plantas em ambiente protegido. Hortic. Bras. 16(1), 24-30.

Medeiros, J.D., S.C.L. Santos, M.J.T. Câmara e M.Z.D. Negreiros. 2007. Produção de melão Cantaloupe influenciado por coberturas do solo, agrotêxtil e lâminas de irrigação. Hortic. Bras. 25(4), 538-543. Doi: 10.1590/ S0102-05362007000400009

Monteiro, S.B. 1995. Irrigação por gotejamento na cultura do melão em estufa e seu feito a produção. Tese de mestrado. Faculdade de Ciências Agronômicas, Universidade Estadual Paulista, Botucatu, Brasil.

Prado, R.D.M. 2008. Nutrição de plantas. Editora UNESP, Jaboticabal, Brasil.

Purquerio, L.F.V. e S.W. Tivelli. 2006. Manejo do ambiente em cultivo protegido. Manual técnico de orientação: projeto hortalimento. Codeagro, São Paulo, Brasil.

Queiroga, F.M.D., J. Novo Junior, S.Â.D.D. Costa, F.D.S. Oliveira Filho, F.H.F. Pereira, A.L.D. Souza Filho e P.B. Maracaja. 2013. Produção e qualidade de frutos de melão Harper em função de doses de boro. Agrop. Cient. Semi. 9(3), 87-93. Doi: 10.30969/acsa.v9i3.377
Ramos, A.R., R.D.C.S. Dias e C.A. Aragão. 2009. Densidades de plantio na produtividade e qualidade de frutos de melancia. Hortic. Bras. 27(4), 560-564. Doi: 10.1590/S0102-05362009000400026

Santos, F.G.B., M.Z. Negreiros, J.F. Medeiros, G.H.S. Nunes, D.C. Medeiros e L.C. Grangeiro. 2015. Produção e qualidade de melão Cantaloupe em cultivo protegido temporariamente com agrotêxtil em Mossoró, Rio Grande do Norte. Rev. Ceres 62(1), 93-100. Doi: 10.1590/0034-737X201562010012

Santos H.G., P.K.T. Jacomine, L.H.C. Anjos, V.A. Oliveira, J.F. Lumbreiras, M.R. Coelho, J.A. Almeida, T.J.F. Cunha e J.B. Oliveira. 2013. Sistema brasileiro de classificação de solos. $3^{a}$ ed. Empresa Brasileira de Pesquisa Agropecuária, Brasília, Brasil.

Sangoi, L., M.A. Gracietti, C. Rampazzo e P. Bianchetti. 2002. Response of brazilian maize hybrids from different eras to changes in plant density. Field Crops Res. 79(1), 39-51. Doi: 10.1016/S0378-4290(02)00124-7

Silva, M.D.C., T. Silva, E.M. Bonfim-Silva e N. Lorraine. 2014. Características produtivas e qualitativas de melão rendilhado adubado com nitrogênio e potássio. Rev. Bras. Eng. Agríc. Ambient. 18(6), 581-587. Doi: 10.1590/S1415-43662014000600003

Silva, I.B., M.Z. Negreiros, K. Kalliany, C.F. Moura, F.C.L. Freitas, G.H.S. Nunes, P.S.L. Silva e L.C. Grangeiro. 2010. Crescimento de pimentão em diferentes arranjos espaciais. Pesq. Agrop. Bras. 45(2), 132-139. Doi: 10.1590/S0100-204X2010000200003

Silva, D.P., J.D. Fonseca, J.C.A. Mota e J.D. Silva. 2003. Densidade de plantio e rendimento de frutos do meloeiro (Cucumis melo L.). Rev. Bras. Frutic. 25(2), 245-247. Doi: 10.1590/S0100-29452003000200015

Vendruscolo, E.P., R.S. Rabelo, L.F.C. Campos, A.P.B. Martins, L.R. Semensato e A. Seleguini. 2017a. Alterações físico-químicas em frutos de melão rendilhado sob aplicação de bioestimulante. Rev. Colomb. Cienc. Hortic. 11(2), 459-463. Doi: 10.17584/rcch.2017v11i2.7413

Vendruscolo, E.P., L.F.C. Campos, A. Seleguini, A.P.B. Martins e S.F.D. Lima. 2017b. Economic viability of muskmelon cultivation in different planting spacing in Brazil central region. Rev. Fac. Nac. Agron. Medellín 70(3), 8319-8325. Doi: 10.15446/rfna.v70n3.62656

Whatley, J.M. e F.R. Whatley. 1982. A luz e a vida das plantas. EDUSP, São Paulo, Brasil. 